\title{
Decreased birefringence of the superficial zone collagen network in the canine knee (stifle) articular cartilage after long distance running training, detected by quantitative polarised light microscopy
}

Jari P A Arokoski, Mika M Hyttinen, Tuomo Lapveteläinen, Péter Takács, Béla Kosztáczky, László Módis, Vuokko Kovanen, Heikki J Helminen

\begin{abstract}
Objective-To investigate the effects of a one year programme of running training (up to $40 \mathrm{~km} /$ day for 15 weeks) on the spatial orientation pattern of collagen and glycosaminoglycans in articular cartilage in different parts of the knee (stifle) and shoulder joints of young beagle dogs.

Methods-Area specific measurements of the optical path difference (= retardation, $\Gamma)$ and the cartilage zone thickness were performed using conventional procedures and a new computer based quantitative polarised light microscopy method. Transmission electron microscopy was used to determine the zonal volume density of collagen fibrils. The concentrations of collagen and hydroxypyridinium crosslinks were investigated biochemically.
\end{abstract}

Results-Running training decreased $\Gamma$ by $24-34 \%(p<0.05)$ in the superficial zone of the lateral femoral condyle articular cartilage and at the centre of the tibial condyles. $\Gamma$ of glycosaminoglycans decreased by $26 \%(p<0.05)$ in the superficial zone of the lateral condyle of the femur, but at the same site the volume density of collagen fibrils was unchanged. Neither the collagen concentration nor the concentration of hydroxypyridinium crosslinks was altered as a result of running. In both control and runner dogs, the thickness and $\Gamma$ values of the superficial zone were greater in the humerus and the femur than in the tibia.

Conclusion-Endurance type running exercise in beagles caused a reduction in the superficial zone birefringence of the articular cartilage, which indicates either a disorganisation or a reorientation of the superficial zone collagen network. Articular cartilage showed marked variability of collagen network organisation over the different knee (stifle) joint articular surfaces.

(Ann Rheum Dis 1996; 55: 253-264)

Articular cartilage matrix consists mainly of collagen and proteoglycans. The negative charge density of the proteoglycan glycosaminoglycans binds large amounts of water, causing a high swelling pressure in the cartilage. ${ }^{1} \mathrm{Up}$ to six different types of collagen molecules are expressed in articular cartilage; about $90 \%$ is type II collagen which is stabilised by mature, non-reducible pyridinoline crosslinks. ${ }^{23}$ The collagen network forms a three dimensional fibrillar network that entraps proteoglycan aggregates and opposes the swelling of proteoglycans, thus providing articular cartilage with tensile stiffness and maintaining its volume. ${ }^{4}$ There is experimental evidence to suggest also that the cohesive strength of the matrix arises from collagen-collagen and collagen-proteoglycan interactions. ${ }^{5} 6$

Benninghoff's widely accepted model of the collagen fibril arrangement in cartilage was based on studies made by polarised light microscopy, ${ }^{7}$ and delineated tangential, transitional, and radial zones in the articular cartilage, in which the collagen fibrils were arranged, respectively, parallel with, oblique to, and perpendicular to the articular surface. The orientation of the long axis of split lines, introduced onto the cartilage surface by pin punctures, corresponded to the orientation of superficial zone collagen fibrils. ${ }^{7}$ Later transmission and scanning electron microscopic observations largely confirmed the results of Benninghoff. ${ }^{8-10}$ Until now, relatively little attention has been paid to the arrangement of the collagen fibrils in different parts of the articular surface of a joint that, understandably, influences the local biomechanical properties and vulnerability of cartilage.

Loss of proteoglycans and the breakdown of the cartilage collagen network is typical of osteoarthritic cartilage. ${ }^{11}$ In osteoarthritis, the concentration of collagen does not change on a dry weight basis until the lesion is severe. ${ }^{12}$ However, several authors have reported that collagen synthesis is increased in osteoarthritic cartilage, ${ }^{12} 13$ though others have reported decreased synthesis. ${ }^{14}$ Initial disorganisation and altered orientation of the articular cartilage collagen fibrils in response to sectioning of the anterior cruciate ligament has been reported. ${ }^{15}$ It is interesting that this process takes place while the cartilage surface still appears smooth and intact.

We recently reported that a programme of running training of young beagle dogs, running up to $40 \mathrm{~km} /$ day for 15 weeks, led to a decrease 
in the glycosaminoglycan content and stiffness of the articular cartilage in the loaded and weight bearing areas of the canine knee (stifle) joint. ${ }^{16}{ }^{17}$ The aim of the present study was to examine whether such long term running training also has any effects on the collagen fibril network of the articular cartilage. We used both conventional polarised light microscopy and a new quantitative computer based image analysis system attached to the polarised light microscope. The volume density and thickness of collagen fibrils in the superficial and deep zone were studied by transmission electron microscopy. Biochemical measurements of collagen and its hydroxypyridinium crosslinks were also made.

\section{Materials and methods}

ANIMALS

Twenty female pure breed beagle dogs from Shamrock Ltd, England, and from the National Laboratory Animal Centre in Kuopio, Finland, were used as experimental animals. There were no anthropometric differences between the dogs purchased from England and their Finnish counterparts (data not shown). The dogs were divided into control $(n=10)$ and running $(n=10)$ groups. The control and runner dogs from the same breeding colony were sister pairs. The dogs were housed in standard cages with a base area of $0.9 \times 1.2 \mathrm{~m}$ and height of $0.8 \mathrm{~m}$. They were fed with commercial dog food (Hankkija, Kolppi, Finland) and water was given ad libitum. The Animal Care and Use Committee of the University of Kuopio approved the experimental design, and the experimental procedure complied with the National Institutes of Health Guidelines. ${ }^{18}$

\section{RUNNING PROGRAMME}

Ten dogs ran on a treadmill according to a scheduled plan, from the age of 15 weeks to 70 weeks, five days a week (fig 1). ${ }^{19}$ The inclination of the treadmill belt was $15^{\circ}$ uphill. During the first five weeks the dogs were adapted to running, after which the running distance was gradually increased up to $40 \mathrm{~km} /$ day, a distance the animals ran for the next 15

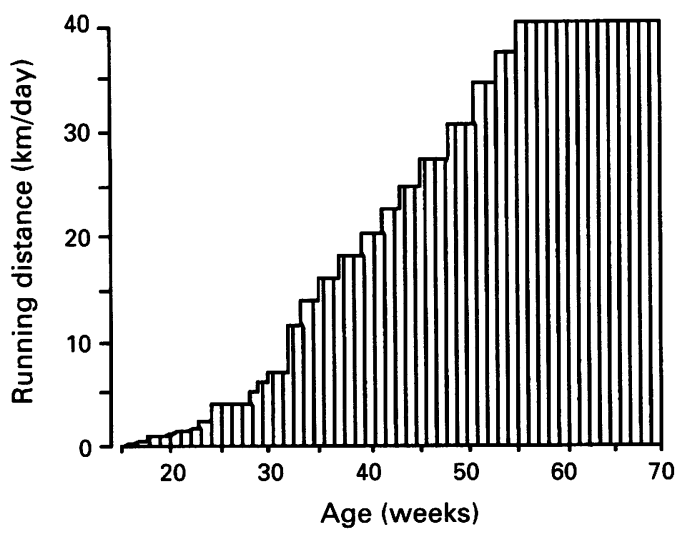

Figure 1 Running programme applied to 10 dogs five days a week for 55 weeks. Starting at age 15 weeks, the dogs' running distance was gradually increased to $40 \mathrm{~km} /$ day, which they ran during the last 15 weeks of the programme. weeks. The final treadmill belt speed was $5.5-6.8 \mathrm{~km} / \mathrm{h}$. The duration of the daily running session was on average seven hours when the daily running distance was $40 \mathrm{~km} /$ day. ${ }^{19}$ Measurement of serum lactate concentrations and pulse rate indicated that the exercise was aerobic. ${ }^{20}$ After each exercise period, the runner dogs rested in individual cages. There was no statistically significant difference in the moving activity of the trained and control animals. ${ }^{20}$

\section{ARTIFICIAL SPLIT LINES}

Four female pure breed beagle dogs, mean age 60 (SD 12) weeks, obtained from the National Laboratory Animal Centre in Kuopio, Finland were investigated for split lines of articular cartilage to demonstrate the general alignment pattern of collagen fibrils within the superficial zone of cartilage. Split lines were produced by inserting a sharp round needle charged with Indian ink into the cartilage surface $^{9}$ at approximately $2 \mathrm{~mm}$ intervals over the femoral and tibial condyles (FMI, FLI, TMI, TLI), the patellar surface of the femur (FPI), and at the head of the humerus (Hum): figure 2 shows the locations. Excess ink was removed by rinsing. The pricked surface of the cartilage was examined face on using a stereomicroscope at a magnification of $\times 10-20$.

PREPARATION OF SAMPLES FOR MICROSCOPY The dogs were killed with an overdose intravenous injection of thiopentone sodium (Hypnostan ${ }^{\circledR}$, Leiras, Turku, Finland) and air insufflation. Immediately after death, the left knee (stifle) and shoulder joints were opened and dissected free. Cartilage samples for histology were taken from six sites from the patellar, femoral, tibial, and humeral surfaces (fig 2), as it has been shown previously that the effect of joint loading is site dependent. ${ }^{21}{ }^{22}$ Before preparation of the specimen, the proximal head of the humerus was stored in Ringer's solution at $4^{\circ} \mathrm{C}$ for $12-14$ hours, for biomechanical testing of the cartilage. ${ }^{17}$

The cartilage samples were prepared by cutting cartilage-bone sections from the articular cartilage, at an angle perpendicular to the surface, using a dental drill equipped with two cutting discs separated by a $1 \mathrm{~mm}$ thick spacer. In the femoral and tibial condyles (FMI, FLI, TMI, TLI), the sections were cut parallel to the split lines in the mediolateral direction, whereas in the patellar surface of the femur (FPI) and at the head of the humerus (Hum), where no clear split line direction was seen, sections were cut in a mediolateral direction. During cutting, the specimens were fixed onto a ball joint specimen holder, which permitted perpendicular cutting of the cartilage sections. During preparation, the specimens were kept moist with ice cold $0.9 \%$ sodium chloride. The samples were fixed in $4 \%$ formaldehyde in $0.07 \mathrm{~mol} / 1$ sodium phosphate buffer, $\mathrm{pH} 7 \cdot 0$, at $4^{\circ} \mathrm{C}$ for 48 hours and decalcified in $10 \%$ EDTA supplied with $4 \%$ formaldehyde in $0.1 \mathrm{~mol} / 1$ sodium phosphate 

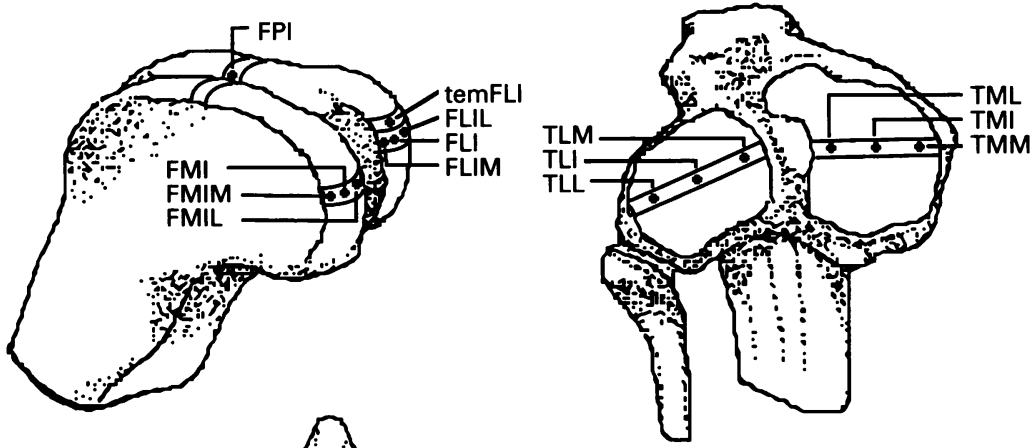

FEMUR

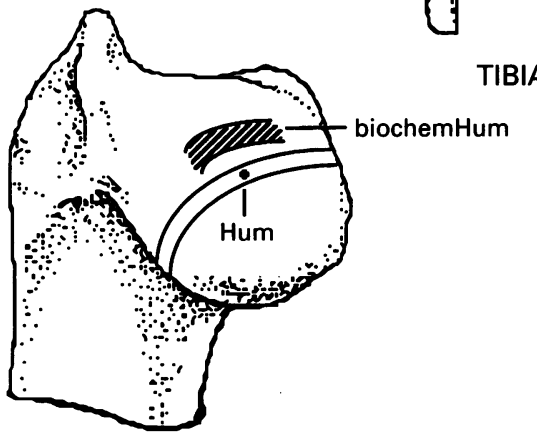

HUMERUS

Figure 2 Sites of the polarised light microscopy analysis (black dots) in the left knee (stifle) and shoulder joints of the dog, and site of the biochemical analysis (cross hatched area) in the left shoulder joint. FPI = Inferior section of the patellar surface of the femur; $F M I=$ summit of the intermediate section of the medial condyle of the femur; FMIM and FMIL = medial and lateral points of the intermediate section of the medial condyle of the femur, respectively; $F L I=$ summit of the intermediate section of the lateral condyle of the femur; FLIM and $F L I L=$ medial and lateral points of the intermediate section of the lateral condyle of the femur, respectively; TMI = central point of the intermediate section of the medial condyle of the tibia; TMM and TML = medial (covered by meniscus) and lateral (not covered by meniscus) points of the medial condyle of the tibia, respectively; TLI = central point of the intermediate section of the lateral condyle of the tibia; TLM and TLL = medial (not covered by meniscus) and lateral (covered by meniscus) points of the lateral condyle of the tibia, respectively; Hum = head of the humerus; biochemHum = site of biochemical analysis at the head of the humerus; tem TLI = site of the transmission electron microscopy analysis at the summit of the intermediate section of the lateral condyle of the femur.

buffer, $\mathrm{pH} 7 \cdot 4$, for 12 days at $4^{\circ} \mathrm{C}$. After alcohol dehydration, the specimens were infiltrated and embedded in Paraplast Plus ${ }^{\circledR}$ wax (Lancer Division of Sherwood Medical, Kildare, Ireland). Although slight loss of glycosaminoglycans occurs during the sample preparation, ${ }^{23}$ this possible loss was identical in both control and runner dogs. Histological sections, $5 \mu \mathrm{m}$ thick, were cut at an angle perpendicular to the articular surface with an LKB 2218 HistoRange microtome (LKBProdukter Ab, Bromma, Sweden), and dried overnight at $37^{\circ} \mathrm{C}$.

TREATMENT OF SECTIONS FOR COLLAGEN POLARISATION MICROSCOPY

Paraplast Plus ${ }^{\circledR}$ wax was removed in xylene at $37^{\circ} \mathrm{C}$ for 24 hours and the sections taken into water through a descending series of alcoholic solutions, before digestion with bovine testicular hyaluronidase (Sigma Chemical Co, St Louis, Mo, USA) to remove glycosaminoglycans from the cartilage. The sections were incubated for 18 hours at $37^{\circ} \mathrm{C}$ in a solution prepared in $0.1 \mathrm{~mol} / 1$ phosphate buffer, $\mathrm{pH} 6.9$, containing testicular hyaluronidase $1000 \mathrm{U} / \mathrm{ml}$, which removes $99.5 \%$ and $95.0 \%$ of the glycosaminoglycans from the superficial and deep zones, respectively. In unstained cartilage sections, this enzyme digestion decreases the birefringence of extracellular matrix by about
$5-10 \%$, indicating that glycosaminoglycans contribute to the form birefringence of the extracellular matrix. ${ }^{24}$ The sections were dehydrated once in $70 \%$ ethanol and three times in absolute alcohol, cleared in xylene, and mounted with DPX ${ }^{\circledR}$ (Gurr, BDH Laboratory Supplies, Poole, England).

\section{HISTOCHEMICAL METHODS FOR} GLYCOSAMINOGLYCAN POLARISATION MICROSCOPY

Cartilage sections were cleared of paraffin in xylene overnight at $37^{\circ} \mathrm{C}$ and the sections were brought to absolute ethanol ( $3 \times$ five minutes) and then to absolute methanol ( $3 \times$ five minutes). Carboxymethylation of the sections was carried out at $37^{\circ} \mathrm{C}$ for 18 hours in a freshly prepared solution of $12.5 \%$ iodoform $\left(\mathrm{CH}_{3} \mathrm{I}\right)$ in absolute methanol saturated with sodium carbonate, followed by rinsing in absolute methanol $\left(3 \times\right.$ five minutes). ${ }^{25}$ The sections were taken through a descending series of alcoholic solutions to distilled water. Glycosaminoglycan staining was carried out using cationic $0 \cdot 1 \%$ toluidine blue at $\mathrm{pH} 5$ for five minutes, ${ }^{24}$ and was stabilised by treatment with a precipitant solution for two to three minutes. ${ }^{26}$ After precipitation, the sections were mounted in $25 \%$ aqueous gum arabic containing $2 \%$ fructose (to prevent cracking of dried gum arabic) and $0.1 \%$ potassium ferricyanide. The preparations were mounted with Canada balsam and covered with a coverslip.

POLARISED LIGHT MICROSCOPY ANALYSIS OF CARTILAGE COLLAGEN FIBRILS

The computerised digital image analysis system for polarised light microscopy consisted of a Leitz Ortholux ${ }^{\circledR} 2$ POL polarised light microscope (Leitz Wetzlar, Wetzlar, Germany) connected to a thermoelectrically cooled Photometrics CH250/A camera (Photometrics Inc, Tucson, AZ, USA) including the Kodak KAF1400 scientific grade charge coupled device (Kodak, Rochester, NY, USA). The camera control and image digitation was carried out via a NuBus interface (Photometrics Ltd) by a Macintosh ${ }^{\circledR}$ II $\mathrm{fX}$ computer and an eight bit grey scale display (Apple Computer Inc, Cupertino, CA, USA). The camera produces 12 bit images (4096 grey shades) and the image can consist of $1317 \times 1035$ pixels. For image capturing, processing, and analysis, and macro routines, IPLab Spectrum ${ }^{\circledR}$ (Signal Analytics Corporation, Vienna, VA, USA) and Microsoft Excel ${ }^{\circledR}$ (Microsoft Corp, WA, USA) softwares were used. During polarised light microscopy, a strain free PL Fluotar $6.3 \times 10.20$ objective was used for the calibration and measurements. For transillumination of the specimens, monochromatic light of wavelength $(\lambda) 591.4$ $\mathrm{nm}$ was used and was adjusted with an interference filter (IL $591.4 \mathrm{~nm}$ (t 1/2-width $10.3 \mathrm{~nm}$ ), Schott, Germany).

In polarised light microscopy, the anisotropic collagen fibrils of articular cartilage cause an optical path difference (retardation) $(\Gamma)$ of the light. ${ }^{27}$ The birefringence of a 
collagen fibril in linearly polarised light is dependent on the angle between the axis of polarisation and the axis of the fibril, and on the geometric thickness of the specimen or the structure. ${ }^{27}$ In cartilage sections, $\Gamma$ depends also on the organisation (orientation) pattern of collagen fibrils or the density of collagen structures in the specimen, or both. ${ }^{24}$ To detect maximum birefringence, the fibril must be oriented at an angle of $45^{\circ}$ to the axis of the polariser or analyser. In our investigation, the fibrils of the surface were measured first by adjusting the cartilage surface exactly at an angle of $45^{\circ}$ to the axis of the polariser, then the chondrocyte columns were set at an angle of $45^{\circ}$ to the axis of the polariser, to measure the birefringence in the deep zone. Birefringence in the middle zone is reduced to zero by lack of coherent orientation of the fibrils, and was not measured (fig 3). Fresnel derived a general equation relating the intensity of incident light to the intensity of the emergent light as altered by the retardation of the object, the compensator, and by the angle of the axis of the analyser. ${ }^{27}$ When the axes of the polariser and analyser intersect at $90^{\circ}$, Fresnel's equation can be written as follows:

$$
\mathrm{I}=\mathrm{a}+\mathrm{b} \mathrm{I}_{0} \sin ^{2}(\alpha) \mid 0^{\circ} \leq \alpha \leq 90^{\circ}
$$

from which follows:

$$
\alpha=\arcsin \left((\mathrm{I}-\mathrm{a}) /\left(\mathrm{b} \mathrm{I}_{0}\right)\right)^{0 \cdot 5}
$$

where $\mathrm{I}_{0}=$ intensity of light entering the polariser; $\mathrm{I}=$ intensity of the light emerging from the analyser (0 to 4095 grey values); $\mathrm{a}=$ observed baseline light intensity when $\alpha$ is zero; $b=$ coefficient that accounts for the camera and microscope adjustments and light absorption due to the whole system; $\alpha=$ rotation angle of the compensator.

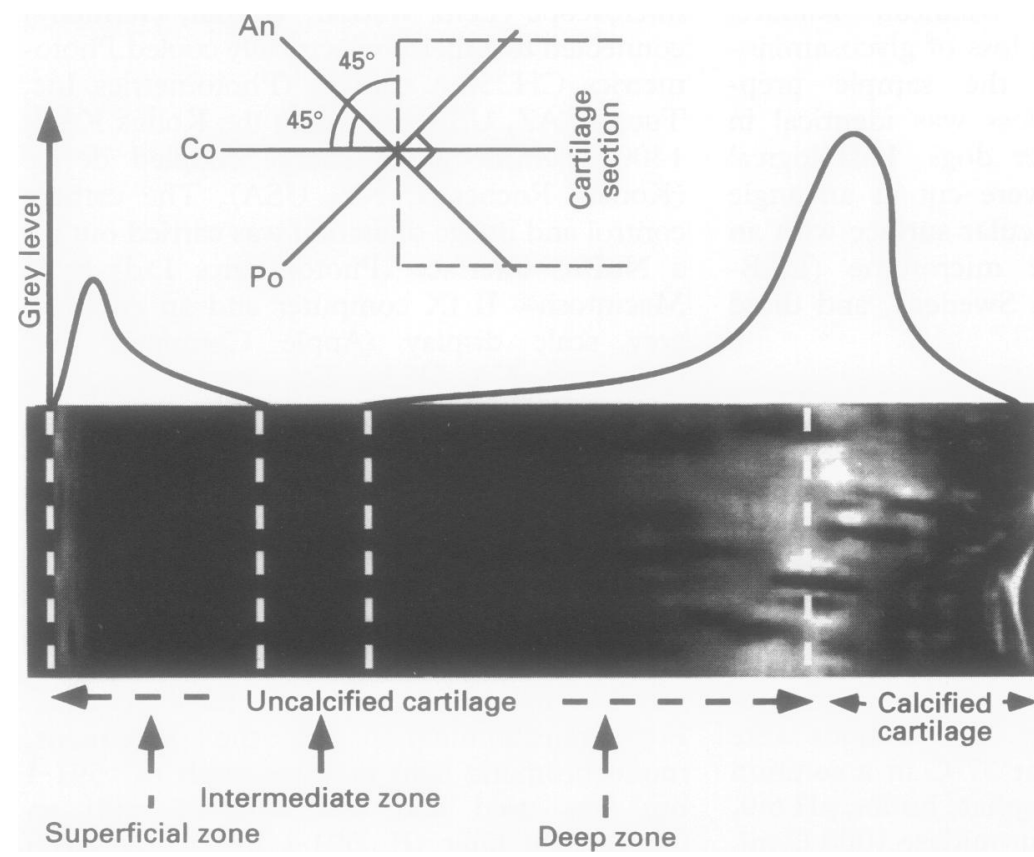

Figure 3 Polarised light microscopy analysis. The cartilage section was positioned as indicated in the drawing, with the cartilage surface always placed an angle of $\pm 45^{\circ}$ to the indicated in the drawing, with the cartilage surface always placed an angle of $\pm 45^{\circ}$ to the axis of both Po and An. The grey levels of the superficial and deep zones were converted to retardation values $(\Gamma)$ of the birefringent material according to the Fresnel equation (see Materials and methods).
Microscope dependent variables such as lamp illumination, microscope alignment, monochromator, magnification, lens aberrations, etc, were kept constant and were taken into account in the final intensity-retardation transformation. To determine the practical mathematical relationship between the measured light intensity (grey scale value) and $\alpha$ values, a rotatable Sénarmont $\lambda / 4$ compensator plate was used as a calibration specimen between the crossed axes of the polariser and analyser. Initially, readout noise from the charge coupled device and other electrical components of the system was determined at each pixel and stored as a separate background image. The compensator was rotated by $0.5^{\circ}$ steps between 0 and $20^{\circ}$. Each compensator rotation was digitised and subtracted from the respective background image. The mean intensity for each compensator step was registered and the compensator angle values were plotted against the respective mean grey intensity. Finally, constants $a$ and $b$ of equation (2) were determined by an iterative process using a Kaleida Graph software (Synergy Software, PA, USA) to determine the standard calibration curve required to convert the observed grey intensity of the specimen into $\alpha$ values. A set of measurements was carried out using manual compensation with the Sénarmont $\lambda / 4$ compensator plate in the samples. The theoretically derived constants were applicable to this real dataset with very close agreement $\left(r^{2}=0.986\right)$, which indicated that virtually no light loss occurred because of unstained samples. Consequently, the optical path difference of the birefringent material $(\Gamma)$ was calculated using the Sénarmont method, ${ }^{27}$ as follows:

$$
\Gamma=(\alpha \lambda) / 180^{\circ}
$$

where $\alpha=$ angle $\left({ }^{\circ}\right)$ (value derived from equation (2)); $\lambda=$ wavelength ( $\mathrm{nm}$ ) of monochromatic light.

The anisotropic areas of superficial and deep zones of articular cartilage were analysed separately to achieve the optimal orientation of the sample. Within the area of measurement, the smallest unit of area was a pixel; in our case, one pixel corresponded to $1.816 \times 1.816 \mu \mathrm{m}$ at the specimen level. The width of the measuring area for the superficial and the deep zones was set to be 150 pixels; its height was determined manually by the height of the corresponding cartilage zone: the superficial zone started at the articular surface (grey level above baseline) and ended at the upper border of the intermediate zone (grey level at baseline/zero); the deep zone started at the tidemark (visible) and ended at the lower border of the intermediate zone (grey level at baseline/zero) (fig 3).

First, the light intensity values for every pixel were recorded and converted to $\Gamma$ values as described above (equations (2) and (3)).

Second, the row (parallel to the cartilage surface) means were calculated for every row of the zone as follows:

$$
\Gamma_{\text {row }}=\Sigma \Gamma_{\text {pixel of the row }} / 150
$$

Further processing of results within a zone consisted of mathematically equalising the number of rows to a predetermined number of subzones (three subzones for the superficial 
zone and three for the deep zone) and calculating a mean for the subzone from the 'row means' of the subzone. When data were pooled, the row mean of the subzone was weighted with the height (or the number of original rows) of the subzone. Results for the superficial and deep zones of articular cartilage were converted to a histogram showing $\Gamma$ values $\left(\mathrm{nm} / \mu \mathrm{m}^{2}\right)$ of the superficial one third $(0-33 \%)$, the middle one third (34-67\%), and the deep one third $(68-100 \%)$ of the zone.

Third, a densitogram (distribution histogram of the pixel light intensity values) was formed from the population of pixels of a zone. From the original densitograms, the mean area adjusted integrated retardation (AIR) value $\left(\Sigma \Gamma_{\mathrm{a}}\right)\left(\mathrm{nm} / \mu \mathrm{m}^{2}\right)$ of birefringent structures was calculated by summing the pixel $\Gamma$ values of the zone and dividing the results by the number of pixels in the corresponding zone,as follows:

$$
\text { AIR }=\Sigma \Gamma_{\text {pixel of the zone }} / \mathrm{n}_{\text {pixels in the zone }}
$$

The fourth parameter recorded for a zone was the thickness of the zone, which was obtained from the number of rows in the measuring area expressed as $\mu \mathrm{m}$ and percentage thickness of the total uncalcified cartilage.

To test the effect of orientation of the specimen on the AIR values of the cartilage surface and deep zone, which was set at an angle of $\pm 45^{\circ}$ to the axis of the polariser and analyser, we rotated the specimens on the stage and made multiple measurements at different angles $\left( \pm 2^{\circ}\right.$, $\pm 5^{\circ}, \pm 8^{\circ}$, and $\pm 10^{\circ}$ ). At the FPI location $\pm 2^{\circ}$, $\pm 5^{\circ}, \pm 8^{\circ}$, and $\pm 10^{\circ}$, we observed decreases of $1 \cdot 1 \%, 3 \cdot 6 \%, 4.3 \%$, and $6 \cdot 1 \%$, respectively, in AIR values in the superficial zone. In the deep zone, angles $\pm 2^{\circ}, \pm 5^{\circ}, \pm 8^{\circ}$, and $\pm 10^{\circ}$ resulted in decreases of $3 \cdot 3 \%, 5 \cdot 1 \%, 8 \cdot 6 \%$, and $13.6 \%$ in AIR values, respectively. To test the error between repeated measurements, superficial and deep zone measurements were carried out six times at the FPI location. Between measurements, the samples were removed, replaced, and refocused. The coefficient of variation (\%) of AIR values between the measurements was $4 \cdot 7 \%$ for the superficial and $0.7 \%$ for the deep zone. To evaluate the range of section thicknesses, six randomly selected sections were analysed, taking the difference in AIR value to reflect the change in section thickness. The coefficient of variation of the AIR values between sections of one tissue block, measured from six different sections at the FPI location, was $7.6 \%$ for the superficial and $11.8 \%$ for the deep zone. The precision of the method was estimated with the relative standard error of the mean (RSE): ${ }^{28} \mathrm{RSE}<10 \%$ was obtained when one to three sections were measured from more than four animals.

CONVENTIONAL POLARISED LIGHT MICROSCOPY ANALYSIS OF CARTILAGE GLYCOSAMINOGLYCANS

The orientation of glycosaminoglycans was

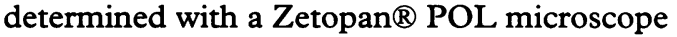
(Reichert, Vienna, Austria), using a magnification of $\times 400$. Because of the high retardation values obtained in some zones, the measurements were made at wavelength $(\lambda)$ $656 \mathrm{~nm}$ using the Sénarmont compensation method. ${ }^{27}$ The optical retardation was determined by rotating the analyser through an angle $\alpha$ until the birefringence was extinguished (the specimen became dark). Consequently, $\Gamma$ values were acquired by determining the value of $\alpha$ in equation (3). In toluidine blue stained cartilage sections, $\Gamma$ depends on the organisation (orientation) pattern of glycosaminoglycan molecules, the glycosaminoglycan concentration, or both. ${ }^{24}$ Analysis was made from the intermediate section of the lateral condyle of the femur; the area analysed covered points FLIL, FLI, and FLIM. The most superficial fraction of the extracellular matrix represented the superficial zone. In the deep zone, the pericellular matrix and the interterritorial matrix were analysed separately. The points where measurements were carried out in different matrix compartments were selected randomly. From each dog, five sections and 20 measurements per section (= 100 measurements per animal) were made in each matrix compartment. The coefficient of variation of $\Gamma$ between sections of one tissue block, measured from five different sections at the FLI location was $3 \cdot 4 \%$ for the extracellular matrix of the superficial zone, $1.6 \%$ for the pericellular matrix of the deep zone, and $4.0 \%$ for the interterritorial matrix of the deep zone. RSE $<10 \%$ was obtained when five sections were measured from more than six animals.

\section{TRANSMISSION ELECTRON MICROSCOPIC}

ANALYSIS

Articular cartilage samples for transmission electron microscopic analysis were taken from the intermediate part of the lateral condyle of the femur (FLI). Cartilage sections $0.5 \mathrm{~mm}$ thick were cut in the same direction as the specimens used in polarised light microscopy samples. Blocks were fixed for 24 hours in $2 \%$ glutaraldehyde in $0.1 \mathrm{~mol} / \mathrm{l}$ sodium cacodylate buffer and decalcified in buffered $4 \cdot 13 \%$ EDTA solution for one day. Samples were postfixed in buffered $1 \%$ osmium tetroxide, dehydrated, and embedded in Epon. Thin vertical sections were cut parallel to the main direction of cut using an ultramicrotome, stained with $1 \%$ tannic acid, uranyl acetate, and lead citrate, ${ }^{29}$ and examined in a JEM1200 EX transmission electron microscope (JEOL Ltd, Tokyo, Japan) at $80 \mathrm{kV}$.

Three electron micrographs were taken systematically from the articular surface to a depth of $15 \mu \mathrm{m}$ (superficial zone), and one electron micrograph was taken 50-60 $\mu \mathrm{m}$ above the tidemark (deep zone), at a primary magnification of $\times 25000$. Collagen fibrils were investigated by randomly superimposing a squared lattice over the photomicrographs (final magnification of $\times 170000$ ). The volume density $\left(V_{v}\right)$ of collagen fibrils was determined as $V_{v}=P_{c} / P_{v}$, where $P_{c}=$ number of test points impinging on collagen fibres and $P_{t}=$ total number of test points hitting the whole tissue. ${ }^{30}$ The average diameter of the longitudinally sectioned collagen fibres $\left(D_{c}\right)$ 
was estimated from each photomicrograph at a final magnification of $\times 170000$.

BIOCHEMICAL ANALYSIS

For the biochemical analysis, the proximal head of the humerus was stored in Ringer's solution at $4^{\circ} \mathrm{C}$ for 12 to 14 hours to test the biomechanical properties of the cartilage. ${ }^{17} \mathrm{~A}$ dental drill equipped with one cutting blade was used to cut $1.5 \times 6.0 \mathrm{~mm}$ sized cartilage-subchondral bone slices from the central area of the head of the humerus near the site of biomechanical testing (fig 2). During preparation, the specimens were kept moist with ice cold Ringer's solution. After storage at $-70^{\circ} \mathrm{C}$, the uncalcified cartilage was carefully separated from the subchondral bone with a surgical knife under a stereomicroscope and stored at $-70^{\circ} \mathrm{C}$ until required for further analyses. The cartilage samples taken for biochemistry were freeze dried, weighed, and hydrolysed in $6 \mathrm{~mol} / \mathrm{l}$ hydrochloric acid at $110^{\circ} \mathrm{C}$ for 24 hours in sealed tubes before the determination of collagen as hydroxyproline, and hydroxypyridinium crosslinks as pyridinoline. Part of the hydrolysate was subjected to partition chromatography, ${ }^{31}$ and pyridinoline was measured by reversed phase high performance liquid chromatography (HPLC) using procedures described previously. ${ }^{32}{ }^{33}$ Quantification was based on the use of pyridinoline standards (a kind gift of Dr Simon Robins, Rowett Research Institute, Aberdeen, Scotland). The pyridinoline concentration was calculated as $\mathrm{mol} / \mathrm{mol}$ of collagen, on the assumptions that hydroxyproline contributes $13 \cdot 3 \%$ of the amino acids of collagen and that collagen has a molecular weight of 300 $\mathrm{kDa}$. Hydroxyproline was analysed by HPLC after an $o$-phthalaldehyde/9-fluorenylmethoxycarbonyl chloride derivatisation system as described originally by Teerlink et $a l^{34}$ and modified by Palokangas et al..$^{33}$

STATISTICAL ANALYSIS

The two tailed non-parametric Wilcoxon matched pairs signed ranks test was used to compare the data of the runner animals with those of their control littermates.

\section{Results}

GROSS FINDINGS

The macroscopic appearance of articular cartilage was normal in both the runners and their controls. Epiphyseal plates were radiographically closed (calcified) around the shoulder and knee (stifle) joints, indicating that the growth of these bones had ceased. Histological surface changes of the cartilage, including exposure of the fibres, was observed in $3.6 \%$ of the runner and $0.1 \%$ of the control animal groups. ${ }^{35}$ This difference was not statistically significant.

DIRECTION OF THE ARTIFICIAL SPLIT LINES In the femoral and tibial condyles, corresponding to the points FMI, FLI, TMI, and
TLI in figure 2, split lines ran across the condyle in the mediolateral direction, whereas in the patellar surface of the femur (point FPI) and at the head of the humerus (point Hum), no clear split line direction could be observed. This split line pattern was constant in each dog investigated.

THICKNESS OF UNCALCIFIED CARTILAGE AND DIFFERENT CARTILAGE ZONES

The thickness of the uncalcified cartilage and its zones varied in the runner and control groups according to the site of the test point (table 1). The mean thickness of the tibial uncalcified cartilage (TMI, TLI) was much greater than that of the femoral (FMI, FLI) and humeral (Hum) cartilages (table 1). The mean thickness of the superficial zone, and the proportion of the superficial zone in the uncalcified cartilage, was greatest at the femoral and humeral test points and least at the tibial test point (tables 1, 2).

In general, running training had no significant effect on the absolute thickness of total uncalcified cartilage and the absolute and percentage thicknesses of the various cartilage subzones (tables 1, 2). However, at the inferior section of the patellar surface of the femur (FPI), the thickness of the deep zone was increased by $25 \cdot 7 \%$ (table 1 ). At the medial point of the intermediate section of the medial condyle of the femur (FMIM), the thickness of the intermediate zone increased significantly, whereas at the lateral point (FMIL), the thickness of the superficial zone had decreased significantly (table 1). At the medial condyle of the tibia covered by meniscus (TMM), the thickness of the deep zone increased significantly, by $17 \cdot 4 \%$ (table 1 ). At the head of the humerus (Hum), the absolute and percentage thicknesses of the deep zone decreased significantly (tables 1,2 ).

COLLAGEN FIBRIL AND GLYCOSAMINOGLYCAN MOLECULE ARRANGEMENT AND $\Gamma$ OF BIREFRINGENCE OF COLLAGEN AND GLYCOSAMINOGLYCANS

As shown earlier by Benninghoff, the deep zone collagen fibrils of the cartilage matrix ran predominantly perpendicularly to the articular surface, and the fibrils curved away obliquely to form gothic arches in the intermediate zone, to run parallel with the articular surface in the surface zone. ${ }^{7}$ This feature was found invariably at each site investigated. In the superficial zone, the birefringence of collagen fibrils decreased as the intermediate zone was approached (figs 3, 4). In the deep zone, birefringence increased throughout the depth of the zone, reaching a peak value at the tidemark (figs 3,4 ).

In the superficial zone, the area adjusted integrated retardation value of birefringence of collagen fibrils varied greatly according to the site of the test point, the deep zone showing least variability. The mean (SD) value of AIR in the superficial zone of the humeral cartilage (Hum) $(\mathrm{n}=9)\left(6.59(0.35) \mathrm{nm} / \mu \mathrm{m}^{2}\right)$, was $25 \%$ greater than that of the femoral cartilage (FPI, 
Table 1 Thickness of uncalcified cartilage determined with polarised light microscopy at different regions of the knee (stifle) and shoulder joints of beagle dogs after long distance running $(40 \mathrm{~km} /$ day $)$

\begin{tabular}{|c|c|c|c|c|c|c|c|c|}
\hline \multirow[t]{3}{*}{ Site of analysis } & \multicolumn{8}{|c|}{ Thickness of uncalcified cartilage $(\mu \mathrm{m})$} \\
\hline & \multicolumn{2}{|l|}{ Total } & \multicolumn{2}{|c|}{ Superficial zone } & \multicolumn{2}{|c|}{ Intermediate zone } & \multicolumn{2}{|l|}{ Deep zone } \\
\hline & $C$ & $R$ & $C$ & $R$ & $C$ & $R$ & $C$ & $R$ \\
\hline \multicolumn{9}{|c|}{ Patellar surface of femur } \\
\hline FPIS $(n=10)$ & $404(64)$ & $460(159)$ & $80(14)$ & $72(17)$ & 67 (19) & $65(30)$ & $257(58)$ & $323(169) \dagger$ \\
\hline \multicolumn{9}{|l|}{ Femoral condyles } \\
\hline FMIM $(n=10)$ & $658(86)$ & $734(216)$ & $87(24)$ & $84(27)$ & $77(40)$ & $108(54)^{\star}$ & $494(92)$ & $542(92)$ \\
\hline FMI $(n=10)$ & $867(94)$ & $832(216)$ & $97(20)$ & $108(33)$ & $47(24)$ & $62(47)$ & $723(101)$ & $662(208)$ \\
\hline FMIL $(n=9)$ & $736(61)$ & $700(157)$ & $107(20)$ & $96(24)^{\star}$ & $52(18)$ & $59(23)$ & $577(71)$ & $545(159)$ \\
\hline FLIM $(n=8)$ & $398(286)$ & $449(87)$ & $77(22)$ & $80(14)$ & $30(21)$ & $46(34)$ & $291(32)$ & $323(74)$ \\
\hline FLI $(n=9)$ & $611(81)$ & $599(153)$ & 77 (13) & $69(15)$ & $105(32)$ & $98(25)$ & $429(72)$ & $432(165)$ \\
\hline FLIL $(n=9)$ & $639(70)$ & 726 (192) & $120(30)$ & $139(45)$ & $59(18)$ & $49(24)$ & $460(84)$ & $538(182)$ \\
\hline \multicolumn{9}{|l|}{ Tibial condyles } \\
\hline$T M M(n=9)$ & $499(100)$ & $555(83)$ & $57(15)$ & $45(20)$ & $52(18)$ & $52(43)$ & $390(112)$ & $458(81)^{\star}$ \\
\hline TMI $(n=10)$ & $1008(110)$ & $1007(101)$ & 47 (13) & $36(9)$ & $25(18)$ & $36(22)$ & $936(109)$ & $935(105)$ \\
\hline TML $(n=10)$ & 1113 (131) & $1163(149)$ & $59(7)$ & $67(18)$ & $13(23)$ & $32(45)$ & 1041 (129) & $1064(121)$ \\
\hline TLM $(n=9)$ & 960 (187) & 99 (178) & $74(31)$ & $61(17)$ & $18(20)$ & $29(32)$ & $868(180)$ & $907(177)$ \\
\hline TLI $(n=9)$ & $780(109)$ & $805(104)$ & 35 (11) & $33(8)$ & $34(10)$ & $40(18)$ & $711(111)$ & $732(94)$ \\
\hline $\operatorname{TLL}(\mathrm{n}=9)$ & $486(57)$ & $565(133)$ & $63(26)$ & $80(22)$ & $93(45)$ & 75 (35) & $330(39)$ & $410(146)$ \\
\hline \multicolumn{9}{|l|}{ Humerus } \\
\hline Hum $(n=9)$ & $506(50)$ & $469(47)$ & $59(8)$ & $60(11)$ & $43(13)$ & $51(17)$ & $404(89)$ & $358(50)^{\star}$ \\
\hline
\end{tabular}

Values are mean $(\mathrm{SD}) ; \mathrm{n}=$ number of paired observations.

$t p=0.05,{ }^{\star} p<0.05$ compared with paried control (two tailed non-parametric Wilcoxon matched pairs signed ranks test).

Table 2 Percentage thickness of the different uncalcified cartilage zones determined with polarised light microscopy at different regions of the knee (stifle) and shoulder joints of beagle dogs after long distance running (40 km/day)

\begin{tabular}{|c|c|c|c|c|c|c|}
\hline \multirow[t]{3}{*}{ Site of analysis } & \multicolumn{6}{|c|}{ Thickness (\%) of uncalcified cartilage } \\
\hline & \multicolumn{2}{|c|}{ Superficial zone } & \multicolumn{2}{|c|}{ Intermediate zone } & \multicolumn{2}{|l|}{ Deep zone } \\
\hline & $C$ & $R$ & $C$ & $R$ & $C$ & $R$ \\
\hline \multicolumn{7}{|l|}{ Patellar surface of femur } \\
\hline FPI $(n=10)$ & $19 \cdot 8(2 \cdot 5)$ & $15 \cdot 7(8 \cdot 2)$ & $16 \cdot 6(3 \cdot 1)$ & $14 \cdot 1(7 \cdot 4)$ & $63 \cdot 6(5 \cdot 6)$ & $70 \cdot 2(12 \cdot 3)$ \\
\hline \multicolumn{7}{|l|}{ Femoral condyles } \\
\hline FMIM $(n=10)$ & $13 \cdot 2(4 \cdot 3)$ & $11 \cdot 4(4 \cdot 9)$ & $11 \cdot 7(5 \cdot 8)$ & $14 \cdot 7(6 \cdot 9)$ & $75 \cdot 1(6 \cdot 6)$ & $73 \cdot 8(6 \cdot 8)$ \\
\hline FMI $(n=10)$ & $11 \cdot 2(2 \cdot 6)$ & $13 \cdot 0(2 \cdot 8)$ & $5 \cdot 4(3 \cdot 1)$ & $7 \cdot 5(8 \cdot 0)$ & $83.4(3.6)$ & $79 \cdot 6(8 \cdot 5)$ \\
\hline $\operatorname{FMIL}(\mathrm{n}=9)$ & $14 \cdot 5(2 \cdot 8)$ & $13 \cdot 7(4 \cdot 8)$ & $7 \cdot 1(2 \cdot 6)$ & $8 \cdot 4(4 \cdot 2)$ & $78 \cdot 3(4 \cdot 1)$ & $77.9(5.9)$ \\
\hline FLIM $(n=8)$ & $19 \cdot 3(6 \cdot 2)$ & $17 \cdot 8(5 \cdot 1)$ & $7 \cdot 5(5 \cdot 5)$ & $10 \cdot 2(5 \cdot 7)$ & $73 \cdot 1(4 \cdot 3)$ & $71.9(5 \cdot 1)$ \\
\hline FLI $(n=9)$ & $12 \cdot 6(2 \cdot 5)$ & $11 \cdot 5(3.0)$ & $17 \cdot 2(4 \cdot 5)$ & $16 \cdot 3(5 \cdot 9)$ & $70 \cdot 2(5 \cdot 7)$ & $72 \cdot 1(7 \cdot 8)$ \\
\hline FLIL (n=9) & $18 \cdot 8(4 \cdot 9)$ & $19 \cdot 1(5 \cdot 4)$ & $9 \cdot 2(3.9)$ & $6 \cdot 7(4 \cdot 1)$ & $72 \cdot 0(6 \cdot 7)$ & $74 \cdot 1(5 \cdot 8)$ \\
\hline \multicolumn{7}{|l|}{ Tibial condyles } \\
\hline TMM $(n=9)$ & $11 \cdot 4(5 \cdot 6)$ & $8 \cdot 1(4 \cdot 8)$ & $10 \cdot 4(4 \cdot 8)$ & $9 \cdot 4(8 \cdot 5)$ & $78 \cdot 2(8 \cdot 1)$ & $82 \cdot 5(5 \cdot 7)$ \\
\hline TMI $(n=10)$ & $4 \cdot 7(1.9)$ & $3.6(0.8)$ & $2.4(1.5)$ & $3 \cdot 6(2 \cdot 4)$ & $92.9(2 \cdot 2)$ & $92 \cdot 9(2 \cdot 3)$ \\
\hline $\mathrm{TML}(\mathrm{n}=10)$ & $5 \cdot 3(1 \cdot 1)$ & $5 \cdot 8(1 \cdot 6)$ & $1 \cdot 2(2 \cdot 0)$ & $2 \cdot 8(3 \cdot 4)$ & $93.5(2.5)$ & $91 \cdot 5(3 \cdot 3)$ \\
\hline $\operatorname{TLM}(n=9)$ & $7 \cdot 7(2 \cdot 0)$ & $6 \cdot 1(2 \cdot 4)$ & $1.9(2.4)$ & $2.9(3.5)$ & $90.4(2.7)$ & $91 \cdot 0(3 \cdot 1)$ \\
\hline $\operatorname{TLI}(\mathrm{n}=9)$ & $4 \cdot 5(1 \cdot 3)$ & $4 \cdot 1(1 \cdot 1)$ & $4.4(1.8)$ & $5.0(1.9)$ & $91 \cdot 2(2 \cdot 2)$ & $90.9(2.3)$ \\
\hline $\operatorname{TLL}(n=9)$ & $13 \cdot 0(5 \cdot 2)$ & $14 \cdot 2(3 \cdot 5)$ & $19 \cdot 1(7 \cdot 7)$ & $13.3(7 \cdot 8)$ & $67 \cdot 9(5 \cdot 5)$ & $72 \cdot 6(9 \cdot 8)$ \\
\hline \multicolumn{7}{|l|}{ Humerus } \\
\hline Hum $(n=9)$ & $11 \cdot 7(2 \cdot 3)$ & $12 \cdot 8(2 \cdot 7)$ & $8 \cdot 5(2 \cdot 2)$ & $10.9(3.9)$ & $79 \cdot 8(2 \cdot 1)$ & $76 \cdot 3(3 \cdot 8)^{\star}$ \\
\hline
\end{tabular}

Values are mean $(\mathrm{SD}) ; \mathrm{n}=$ number of paired observations.

$\mathrm{C}=$ Control; $\mathrm{R}=$ runner; $\oint$ See figure 2 for abbreviations.

${ }^{\star} \mathrm{p}<0.05$ compared with paired control (two tailed non-parametric Wilcoxon matched pairs signed rank test).

FMI, FLI) $(\mathrm{n}=29)\left(4.96(0.36) \mathrm{nm} / \mu \mathrm{m}^{2}\right)$ and $52 \%$ greater than that of the tibial cartilage (TMI, TLI) $(\mathrm{n}=19)\left(3 \cdot 14(0 \cdot 27) \mathrm{nm} / \mu \mathrm{m}^{2}\right)$ in the control group. The zonal distribution of $\Gamma$ $\left(\mathrm{nm} / \mu \mathrm{m}^{2}\right)$ showed that the difference was greatest in the outermost or superficial one third of the superficial zone (fig 4).

After the running training, the AIR value of the collagen fibrils decreased by $24 \%$ on the summits of the lateral femoral condyle (FLI), and by between $25 \%$ and $34 \%$ on the central points of the tibial condyles (TMI, TLI) (table 3, fig 5). In addition, at the medial point of the lateral condyle of the tibia (TLM), the area not covered by meniscus, AIR values decreased by $30 \%$ in the superficial zone (table 3). The reduction in AIR value was most pronounced in the first and second one thirds of the superficial zone (fig 4). At the marginal areas of the medial and lateral condyles of the femur (FMIM, FMIL, FLIM, FLIL), the AIR values were not changed after running. At the head of the humerus (Hum), $\Gamma$ was significantly decreased in the second one third of the superficial zone (fig 4). Running had no effect on the value of $\Gamma$ in the deep zone of articular cartilage of any of the test points (table 3, fig 4).

In the superficial zone, the preferential orientation axis of the sulphated glycosaminoglycan molecules seemed to be parallel to the articular surface. In the pericellular matrix of the deep zone, glycosaminoglycan molecules were arranged tangentially around the chondrocytes, whereas in the interterritorial matrix the pattern of orientation of glycosaminoglycans was perpendicular to the articular surface. After running training, at the intermediate point of the lateral condyle of the femur (FLI), mean (SD) $\Gamma$ of glycosaminoglycans in the superficial zone matrix decreased significantly from $40 \cdot 0(10 \cdot 3) \mathrm{nm}$ to $29 \cdot 7(9 \cdot 8)$ $\mathrm{nm}(\mathrm{p}=0.036)$ (fig 6). In the interterritorial matrix of the deep zone, $\Gamma$ of glycosaminoglycans decreased from $33.7(8.7) \mathrm{nm}$ to 32.4 $(5 \cdot 0) \mathrm{nm}$, and in the pericellular matrix of the deep zone it decreased from $60 \cdot 6(11 \cdot 3) \mathrm{nm}$ to $51.8(9 \cdot 0) \mathrm{nm}$, but these changes were not significant (fig 6 ). 

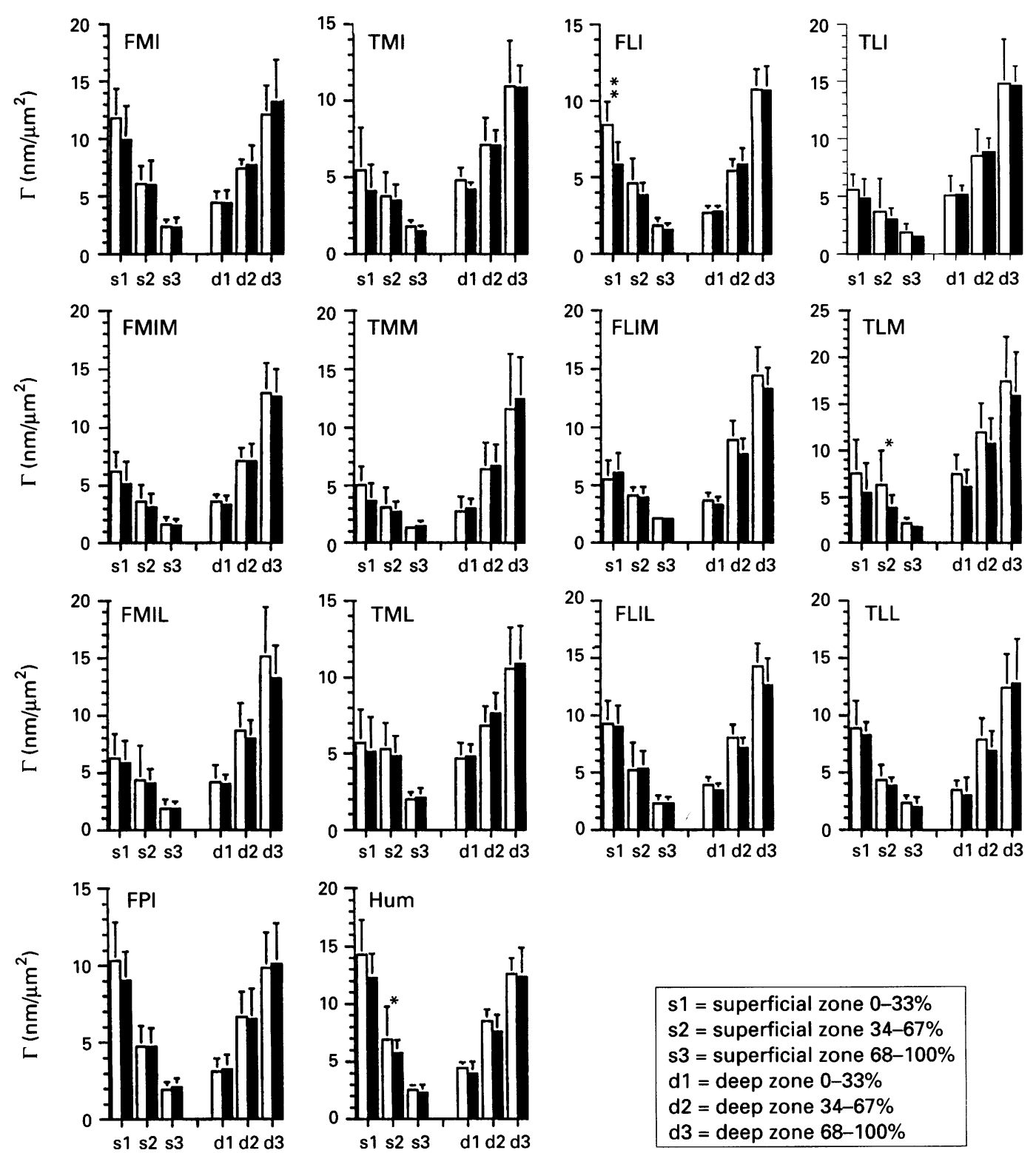

s1 $=$ superficial zone $0-33 \%$
s2 $=$ superficial zone $34-67 \%$
s3 $=$ superficial zone $68-100 \%$
d1 $=$ deep zone $0-33 \%$
d2 $=$ deep zone $34-67 \%$
d3 $=$ deep zone $68-100 \%$

Figure 4 Histogram of the retardation values $(\Gamma)\left(\mathrm{nm} / \mu^{2}\right)$ of the birefringence in the superficial and deep zones (divided into three subzones) of articular cartilage in different regions of the knee and shoulder joints of beagle dogs. Abbreviations as in figure 2. ${ }^{*} p<0.05 ;{ }^{*} p<0.01$ (two tailed non-parametric Wilcoxon matched pairs signed ranks test). $\square=$ Control dog; = runner dog

VOLUME DENSITY AND DIAMETER OF COLLAGEN FIBRILS

The volume density $\left(\mathrm{V}_{\mathrm{v}}\right)$ of superficial collagen fibrils was slightly decreased at the intermediate point of the lateral condyle of the femur (table 4). In the deep zone, $V_{v}$ of the collagen fibrils was unchanged. The average diameter of the longitudinally sectioned collagen fibres $\left(D_{c}\right)$ was unchanged (table 4$)$.

CONCENTRATION OF COLLAGEN AND PYRIDINOLINE

The concentration of collagen or pyridinoline did not differ in the cartilage samples of the proximal head of the humerus from the trained and untrained animals (table 5).

\section{Discussion}

The dogs in this study were young when they entered the study: age 15 weeks, which is about equivalent to an eight year old child. Skeletal maturity in a beagle is generally achieved by 10 months, which is more or less comparable to 19 years in a human. ${ }^{36}$ The results of this study may therefore be extrapolated, with caution, to human adolescents.

The new computer based polarised light microscopic method used in this study provided a quantitative and objective means of investigating the organisation of collagen fibrils in articular cartilage. During polarised light microscopy, cartilage sections could be oriented accurately, and the image provided a good overall impression of the collagen arrangement. However, the technique has some limitations. First, section thickness must be kept constant as far as possible, and a number of sections must be measured to meet the demands of the statistical design and treatment of the results. Second, the orientation of the specimen is critical, as sections cut parallel to the artificial split lines result in greater birefringence for the superficial zone than do those cut perpendicularly. ${ }^{37}$ In this study, 
Table 3 Mean area adjusted integrated retardation value $\left(\Sigma \Gamma_{a}\right)(A I R)$ of the birefringent structure at different sites and zones of articular cartilage of the knee (stifle) and shoulder joints of beagle dogs after long distance running (40 km/day)

\begin{tabular}{|c|c|c|}
\hline \multirow[t]{2}{*}{ Site of analysis } & \multicolumn{2}{|l|}{$A I R\left(n m / \mu m^{2}\right)$} \\
\hline & Superficial zone & Deep zone \\
\hline \multirow{2}{*}{\multicolumn{3}{|c|}{ Patellar surface of femur }} \\
\hline & 0.95 & $1 \cdot 02$ \\
\hline \multicolumn{3}{|l|}{ Femoral condyles } \\
\hline $\operatorname{FMIM}(\mathrm{n}=10)$ & $0 \cdot 80$ & 0.98 \\
\hline FMI $(n=10)$ & 0.91 & 1.09 \\
\hline FMIL $(n=9)$ & $0 \cdot 96$ & 0.90 \\
\hline FLIM $(n=8)$ & $1 \cdot 02$ & 0.91 \\
\hline FLI $(n=9)$ & $0 \cdot 76^{\star}$ & $1 \cdot 00$ \\
\hline FLIL $(n=9)$ & 0.94 & 0.93 \\
\hline \multicolumn{3}{|l|}{ Tibial condyles } \\
\hline TMM $(n=9)$ & 0.79 & $1 \cdot 04$ \\
\hline TMI $(\mathrm{n}=10)$ & $0 \cdot 66^{\star}$ & 0.98 \\
\hline TML $(n=10)$ & $0 \cdot 93$ & $1 \cdot 05$ \\
\hline $\operatorname{TLM}(\mathrm{n}=9)$ & $0 \cdot 70^{\star}$ & 0.91 \\
\hline TLI $(n=9)$ & $0 \cdot 75^{\star}$ & $1 \cdot 01$ \\
\hline TLL $(n=8)$ & $0 \cdot 86$ & 0.92 \\
\hline \multicolumn{3}{|l|}{ Humerus } \\
\hline $\operatorname{Hum}(n=9)$ & $0 \cdot 88$ & 0.94 \\
\hline
\end{tabular}

Values are ratios between the mean values of the runner and control groups; $\mathrm{n}=$ number of paired observations.

See figure 2 for abbreviations. Significant difference from unity: ${ }^{\star} \mathrm{p}<0.05$ (two tailed non-parametric Wilcoxon matched pairs signed rank test).

reproducibility of the cutting procedure was ensured by determining the split line pattern in normal canine knee (stifle) and shoulder articular cartilage from the main weight bearing sites of analysis, and by always cutting the experimental sections parallel to these main directions (fig 2). The split line pattern was constant, as has been reported previously in dogs. ${ }^{3 i}$

The present findings support the Benninghoff arcade model of collagen architecture in articular cartilage. ${ }^{\top}$ However, the thickness and organisation of the cartilage zones showed marked variation in different articular surfaces. The relative thickness of the superficial zone in the humerus and the femur was significantly greater than that in the tibia. The pattern of organisation of collagen is

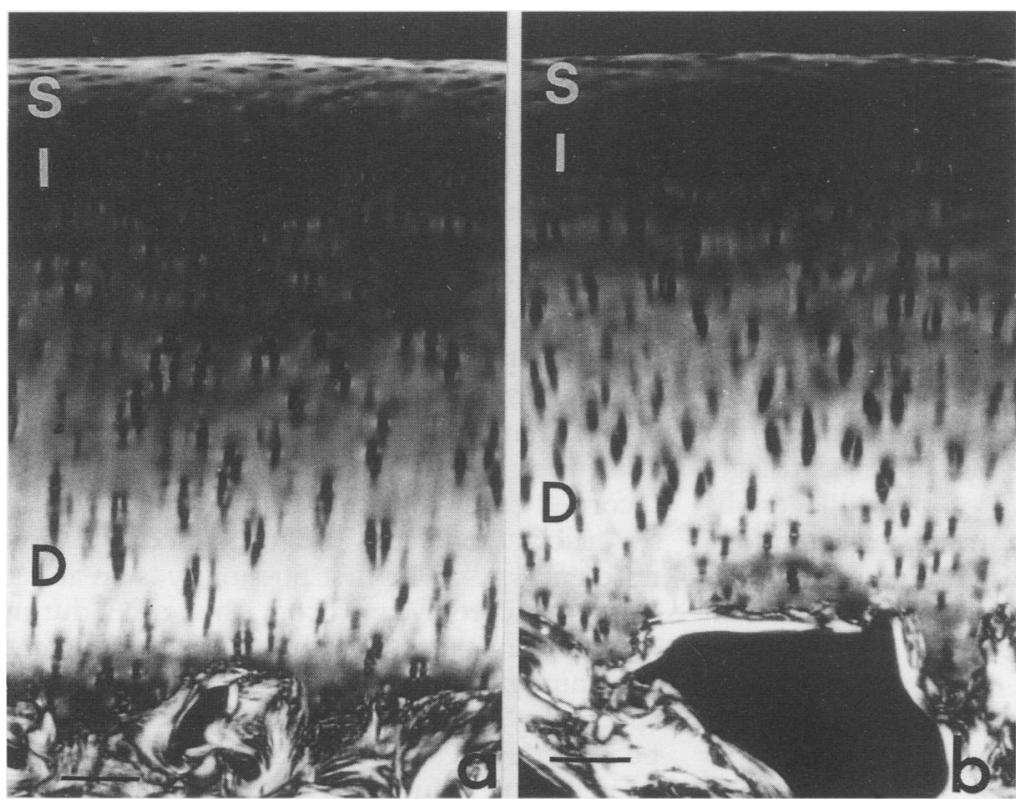

Figure 5 Polarised light micrographs taken from unstained sections of the articular cartilage at the summit of the intermediate section of the lateral condyle of the femur (point FLI) from a control dog (left) and a muner dog (right). $S=$ superficial zone; $I=$ intermediate zone; $D=$ deep zone. Birefringence was usually weak in the superficial zone of the runner. Scale bar represents $100 \mu \mathrm{m}$.

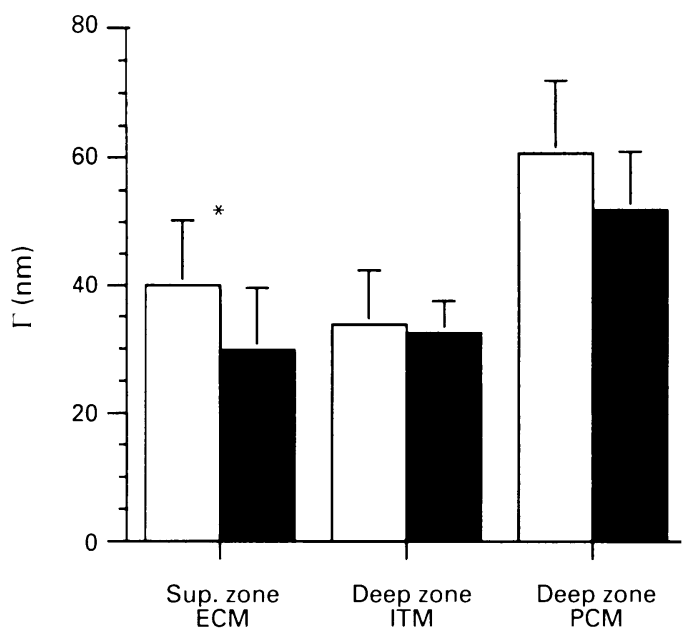

Figure 6 Retardation values $(I)$ of the birefringence (mean (SD)) measured from different matrix compartments of articular cartilage stained for sulphated glycosaminoglycans with toluidine blue at the intermediate section of the lateral condyle of the femur from control ( $\square$ ) and runner $(\mathbf{D})$ dogs. ECM = extracellular matrix; ITM = interterritorial matrix; $P C M=$ pericellular matrix. ${ }^{*} p<0.05$ (two tailed non-parametric Wilcoxon matched pairs signed ranks test).

probably closely related to the local functional requirements of the tissue: an area that is regularly subjected to high levels of shear stress shows a higher degree of collagen orientation, a thicker superficial zone, greater proteoglycan concentrations, ${ }^{38}$ and greater stiffness ${ }^{17}$ than one that is mostly subjected to weight bearing, such as the tibial plateau, which is also protected by the meniscus. ${ }^{39}$ Failure of the collagen network causes a decrease in the tensile stiffness and strength of the tissue. ${ }^{40}$ The instantaneous deformation of cartilage is believed to be controlled by the collagen network; in particular, the superficial collagen network influences the tensile stiffness of cartilage. ${ }^{41}+2$ It is quite possible, even probable, that the slightly decreased instant stiffness at points FLI and TLI noted previously in these dogs is associated with the reduction in superficial zone birefringence observed there. ${ }^{17}$

In humans, the contact area and pressure appear to increase in particular in the lateral

Table 4 Volume density ( $V$ ) and diameter of the longitudinally sectioned collagen fibrils $(D)$ at the intermediate point of the lateral condyle of the femur (FLI) after long distance running $(40 \mathrm{~km} / \mathrm{day})$

\begin{tabular}{|c|c|c|}
\hline & $\begin{array}{l}\text { Controls } \\
(n=8)\end{array}$ & $\begin{array}{l}\text { Runners } \\
(n=8)\end{array}$ \\
\hline \multicolumn{3}{|c|}{ Volume density of collagen fibrils $(\%)$} \\
\hline Superficial zone & $87 \cdot 6(5 \cdot 0)$ & $82 \cdot 2(8 \cdot 7)$ \\
\hline Deep zone & $94 \cdot 3(2 \cdot 8)$ & $92 \cdot 6(3 \cdot 7)$ \\
\hline \multicolumn{3}{|c|}{ Diameter of collagen fibrils $(\mathrm{nm})$} \\
\hline Superficial zone & $10 \cdot 7(2 \cdot 7)$ & $11 \cdot 4(3 \cdot 6)$ \\
\hline Deep zone & $35.3(15.8)$ & $33 \cdot 5(13 \cdot 2)$ \\
\hline
\end{tabular}

Values are mean $(\mathrm{SD}) ; \mathrm{n}=$ number of paired animals.

Table 5 Concentration of collagen ( $\mu \mathrm{g} / \mathrm{mg}$ tissue dry weight) and pyridinoline crosslinks (mol/mol collagen) at the head of the humerus of beagle dogs after long distance running $(40 \mathrm{~km} / \mathrm{day})$

\begin{tabular}{lll}
\hline & Collagen & Pyridinoline \\
\hline Controls $(\mathrm{n}=10)$ & $473(32)$ & $1 \cdot 31(0 \cdot 21)$ \\
Runners $(\mathrm{n}=10)$ & $481(22)$ & $1 \cdot 30(0 \cdot 17)$ \\
\hline
\end{tabular}

Values are mean $(\mathrm{SD}) ; \mathrm{n}=$ number of paired animals. 
compartment of the knee when the load increases. ${ }^{43}$ As judged by kinesiological analysis of the canine knee (stifle), the patellofemoral compartment and the summits of the femoral and tibial condyles probably carry the heaviest loads. ${ }^{38}$ The present study has demonstrated that running training of $40 \mathrm{~km} /$ day for 15 weeks caused a significant reduction of the superficial zone birefringence of the articular cartilage. The decreased birefringence occurred mostly at the summit of the lateral condyle of the femur (FLI) and at the central areas of the tibial condyles (TMI, TLI, TLM), and was most pronounced in the outermost or the second one third of the superficial zone. Birefringence of the superficial zone was also significantly decreased in the head of the humerus. At the margin of condylar areas the birefringence of neither the superficial nor the deep zone collagen changed. In addition, the femoropatellar cartilage revealed no significant changes after running. Thus the effect of running exercise on collagen was highly site dependent, as has been proposed before. ${ }^{22}$

Neither the total concentration of collagen nor the total hydroxypyridinium crosslink concentration was altered at the head of the humerus, though the birefringence of the cartilage superficial zone decreased. The biochemical measurements of cartilage collagen were performed in specimens containing both the superficial and the deeper zones. Consequently, the changes observed in the superficial zone (collagen) birefringence at the cartilage surface cannot be compared directly with the biochemical concentration of collagen. In the lateral condyle of the femur (point FLI), where the reduction in AIR values was most pronounced in the first and second one thirds of the superficial zone, the volume density of the most superficial collagen fibrils was slightly, but not significantly, decreased. These data suggest that the decrease in birefringence observed in the superficial zone of the runner dogs can be explained in part, but not completely, by a change in the collagen concentration.

It is not known what causes the decrease in the birefringence in the superficial zone of articular cartilage after long distance running. A derangement or even a disorganisation of the superficial collagen network may be the cause. Our previous observations support this view. Säämänen $e t$ al studied beagle dogs undergoing $20 \mathrm{~km} /$ day of running exercise, and found that there was an increased water content and a decreased concentration of collagen in the lateral femoral condyle articular cartilage, indicative of a loosening of the collagenous network after the running training. ${ }^{22}$ Strenuous running training of adult mongrel dogs had previously been shown to cause fibrillation in the femoral head cartilage. ${ }^{44}$

Another reasonable explanation of the decrease in the birefringence would be that, during running training, the individual collagen fibrils retain their normal structure but, through degradation and resynthesis, change their global orientation, resulting in a decrease in birefringence. This implies that a reorientation or reorganisation of collagen fibrils would take place, which may be a physiological functionally adaptive response to long distance running training. These changes are possibly produced during the attainment of skeletal maturity, rather than after it is attained. In general, the prevailing view is that the metabolism of collagen in articular cartilage is slow. ${ }^{45}$ The collagen framework of canine articular cartilage is laid down early during growth and the collagen turnover in mature cartilage is slow. ${ }^{45}$

The mechanism that accounts for collagen fibril disorganisation or reorientation remains to be elucidated. As suggested earlier, a possible stiffening of the subchondral plate can cause a reduction in the shock absorbing capacity of the bone end. ${ }^{46} 47$ In this investigation, the histomorphometric parameters of subchondral bone showed changes such as an increase in the trabecular bone and osteoid volume, increased bone formation, and an increased area of resorption surface. This is indicative of bone remodelling. ${ }^{35}$ Stiffening of the subchondral bone will expose the superficial collagen fibrils to excessive peak loads, perhaps sufficiently large to lead to breakdown of individual fibrils in the cartilage surface. This mechanism seems even more plausible in the light of the simultaneous depletion of superficial zone glycosaminoglycans, ${ }^{16}$ and the softening of the cartilage: ${ }^{17}$ proteoglycan loss in the superficial zone reduces the swelling pressure of cartilage and the cartilage softens. ${ }^{17}$ Greater amounts of energy are absorbed in the cartilage during weight bearing, and the collagen fibrils may be exposed to peak loads sufficiently large to cause disturbance or reorientation in the collagen network. These peak loads may even be sufficient to injure individual collagen fibrils. Proteoglycan loss in the superficial zone exposes the collagen fibrils and makes them vulnerable, not only to mechanical forces, but also to attack by degradative enzymes. Catabolic factors such as matrix metalloproteinases (for example stromelysin-1 and collagenase) released from the chondrocytes by cytokines (for example interleukin-1) are able to degrade most of the cartilage components such as proteoglycans and various types of collagen (II, IX, X, and XI). ${ }^{4849}$

Long distance running training causes depletion of glycosaminoglycans at the superficial and intermediate zones at the point FLI, ${ }^{16}$ and also alters the optical anisotropy of the glycosaminoglycans. The decreased optical anisotropy of glycosaminoglycan molecules recorded from the extracellular matrix of the superficial zone can be explained in three different ways. The first possibility is an actual loss of proteoglycans from this zone during long distance running. In this case, less glycosaminoglycan will be stained in histological specimens and thus less optical anisotropy will be recorded. The second possibility is that the decrease in induced glycosaminoglycan birefringence is attributable to the decreased organisation pattern of the interacting collagen; it has been shown repeatedly that the degree of orientation of glycosaminoglycans is 
strongly dependent on the degree of orientation of the collagen fibrils. ${ }^{24} \mathrm{~A}$ third possibility is that the glycosaminoglycan orientation pattern changes independently of that of collagen. Using the present technique, we can only conclude that the spatial orientation or concentration of the sulphated glycosaminoglycans is decreased in the extracellular matrix of the superficial zone of the articular cartilage in the runner group. This can be regarded as a sign of cartilage surface disturbance.

Disorganisation or reorientation of the collagen network may be a marker for future derangement of the cartilage structure, fibrillation, injury, and osteoarthritis. ${ }^{15} 50$ The latest human epidemiological studies support the idea that various types of endurance sports and occupations that combine knee bending with prolonged heavy loading are risk factors for the development of lower limb osteoarthrosis. ${ }^{51-53}$

This study was supported by research grants from the Finnish Research Council for Physical Education and Sports, Ministry of Education, the Medical Research Council of the Academy of Education, the Medical Research Council of the Academy
of Finland, the North Savo Fund of the Finnish Cultural of Finland, the North Savo Fund of the Finnish Cultural Foundation, and the Finnish
Orthopaedics and Traumatology.

1 Maroudas A. Balance between swelling pressure and collagen tension in normal and degenerate cartilage. Nature 1976; 260: 808-9.

2 Eyre D R, Dickson I R, Van Ness K. Collagen cross-linking in human bone and articular cartilage. Age-related changes in the content of mature hydroxypyridinium residues. Biochem f 1988; 252: 495-500.

3 Eyre D R, Wu J J, Woods P. Cartilage-specific collagensstructural studies. In: Kuettner K E, Schleyerbach R, Peyron J G, Hascall V C, eds. Articular cartilage and osteoarthritis. New York: Raven Press, 1992; 119-31.

4 Myers R R, Mow V C. Biomechanics of cartilage and its response to biomechanical stimuli. In: Hall $\mathrm{B} \mathrm{K}$, ed. Cartilage. Structure, function and biochemistry. New York: Academic Press, 1983; 313-41.

5 Broom N D, Silyn-Roberts H. Collagen-collagen versus collagen-proteoglycan interactions in the determination of cartilage strength. Arthritis Rheum 1990; 33: 1512-7.

6 Guilak F, Ratcliffe A, Lane N, Rosenwasser M P, Mow V C. Mechanical and biochemical changes in the superficial zone of articular cartilage in canine experimental osteoarthritis. F Orthop Res 1994; 12: 474-84.

7 Benninghoff A. Form und Bau der Gelenkknorpel in ihren Beziehungen zur Funktion. Erste Mitteilung: Die modellierenden und formerhaltenden Faktoren des Knorpelreliefs. Z Gesamte Anatomie Abt 1 1925; 76: 43-63.

8 reliefs. Z Gesamte Anatomie Abt 1 1925; 76: 43-63. electron microscope study. II. The territorial fibrillar electron microscope study. II. The

9 Meachim G, Denham D, Emery I H, Wilkinson P H. Collagen alignments and artificial splits at the surface of human articular cartilage. $\mathcal{F}$ Anat 1974 ; 118: 101-18.

10 Minns R J, Steven F S. The collagen fibril organization in human articular cartilage. $\mathcal{F}$ Anat 1977; 123: 437-57.

11 Mankin $\mathrm{H} \mathrm{J}$, Thrasher A Z. Water content and binding in normal and osteoarthritic human cartilage. $\mathcal{f}$ Bone foint Surg Am 1975; 57: 76-9.

12 Lippiello L, Hall D, Mankin H. Collagen synthesis in normal and osteoarth

13 Floman Y, Eyre D R, Climcher M J Basic science and pathology. Induction of osteoarthrosis in the rabbit knee pathology. Induction of osteoarthrosis in the rabbit knee Orthop 1980; 147: 278-86.

14 Burton-Wurster N, Hui-Chou C S, Greisen H A, Lust G. Reduced deposition of collagen in the degenerated articular cartilage of dogs with degenerative joint disease. Biochim Biophys Acta 1982; 718: 74-84.

15 Orford C R, Gardner D L, O'Connor P. Ultrastructural changes in dog femoral condylar cartilage following anterior cruciate ligament section. F Anat 1983; 137: 653-63.

16 Arokoski J, Kiviranta I, Jurvelin J, Tammi M, Helminen H $J$. Long-distance running causes site-dependent decrease of cartilage glycosaminoglycan content in the knee joints of beagle dogs. Arthritis Rheum 1993; 36: 1451-9.

17 Arokoski J, Jurvelin J, Kiviranta I, Tammi M, Helminen $H$ J. Softening of the lateral condylar articular cartilage in the canine knee joint after long distance (up to $40 \mathrm{~km} / \mathrm{day}$ ) running training lasting one year. Int $\mathcal{F}$ Sports Med 1994; 15: 254-60.

$18 \mathrm{NIH}$ publication No 78-23. Guide for care and use of laboratory animals. Bethesda: US Government Printing Office, 1985.
19 Arokoski J, Kiviranta I, Laakkonen J, et al. A ten-track treadmill for running training of dogs. Lab Anim Sci 1991; 41: 246-50.

20 Arokoski J, Miettinen P V A, Säämänen A-M, et al. Effects of aerobic long distance running training (up to
$40 \mathrm{~km} /$ day) of 1 -year duration on blood and endocrine $40 \mathrm{~km} /$ day) of 1 -year duration on blood and endocrine
parameters of female beagle dogs. Eur $¥$ Appl Physiol 1993; 67: 321-9.

21 Säämänen A-M. Articular cartilage proteoglycans and joint loading. A study in young rabbits and dogs (thesis). Kuopio, Finland: University of Kuopio, 1989.

22 Säämänen A-M, Kiviranta I, Jurvelin J, Helminen $\mathbf{H ~ J}$, Tammi M. Proteoglycan and collagen alterations in canine knee articular cartilage following $20 \mathrm{~km}$ daily running exercise for 15 weeks. Connect Tissue Res 1994; 30: 191-201.

23 Király K, Lammi M, Arokoski J, et al. Safranin O reduces loss of glycosaminoglycans from bovine articular cartilage during histological specimen. Histochem $f$ 1996. In press.

24 Módis L. Extracellular matrix: a polarization microscopic approach. Boca Raton: CRC Press, 1991.

25 Terner J Y. Histochemical alkylation: a study of methyliodide and its effects on tissues. $\mathcal{F}$ Histochem Cytochem 1964; 12: 504-10.

26 Romhányi G. Über die submicroskopische strukturelle Grundlage der metachromatischen Reaktion. Acta Histochemica 1963; 15: 201-33.

27 Bennett H S. Methods applicable to the study of both fresh and fixed materials. The microscopical investigation of biological materials with polarized light. In: McClung J R, ed. McClung's handbook of microscopical technique. New York: Paul B Hoeber, 1950; 591-677.

28 Mathieu O, Cruz-Orive L M, Hoppeler H, Weibel E R Measuring error and sampling variation in stereology: comparison of the efficiency of various methods for planar image analysis. 7 Microsc 1981; 121: 75-88.

29 Afzelius B A. Section staining for electron microscopy using tannic acid as a mordant: a simple method for visualization of glycogen and collagen. Microsc Res Tech 1992; 21: 65-72

30 Weibel E R. Stereological methods. London: Academic Press, 1979.

31 Black D, Duncan A, Robins S. Quantitative analysis of the pyridinium crosslinks of collagen in urine using ion-paired reversed-phase high-performance liquid chromatography. Analyt Biochem 1988; 169: 197-203.

32 Eyre D R, Koob T J, Van Ness K P. Quantitation of hydroxypyridinium crosslinks in collagen by highperformance liquid chromatography. Analyt Biochem 1984; 137: 380-8.

33 Palokangas H, Kovanen V, Duncan R, Robins S P. Age related changes in the concentration of hydroxypyridinium crosslinks in functionally different skeletal muscles. Matrix 1992; 12: 291-6.

34 Teerlink T, Tavenier P, Netelenbos J C. Selective determination of hydroxyproline in urine by high-performance liquid chromatography using precolumn derivatization. Clin Chim Acta 1989; 183: 309-16.

35 Oettmeier R, Arokoski J, Roth A J, Helminen H J, Tammi M, Abendroth $\mathrm{K}$. Quantitative study of articular cartilage and subchondral bone remodeling in the knee joint of dogs after strenuous running training. 7 Bone Miner Res 1992; 7(Suppl): S419-24.

36 Meschan I. An atlas of normal radiographic anatomy. Philadelphia: Saunders, 1960.

37 Speer D P, Dahners L. The collagenous architecture of articular cartilage. Correlation of scanning electron microscopy and polarized light microscopy observations. microscopy and polarized light
Clin Orthop 1979; 139: 267-75.

38 Kiviranta I, Tammi $M$, Jurvelin J, Säämänen A-M, Helminen $\mathrm{H}$ J. Moderate running exercise augments glycosaminoglycans and thickness of articular cartilage in the knee joint of young beagle dogs. F Orthop Res 1988; 6: 188-95.

39 Seedhom B B. Transmission of the load in the knee joint with special reference to the role of the menisci. Part I: anatomy, analysis and apparatus. Proc Inst Mech Eng [H] 1979; 8: 207-19.

40 Kempson G E. Relationship between the tensile properties of articular cartilage from the human knee and age. $A n n$ Rheum Dis 1982; 41: 508-11.

41 Mizrahi J, Maroudas A, Lanir Y, Ziv I, Webber T J. The "instantaneous" deformation of cartilage: effects of collagen fiber orientation and osmotic stress. Biorheology collagen fiber orienta

42 Bader D L, Kempson G E, Egan J, Gilbey W, Barrett A J. The effects of selective matrix degradation on the shortterm compressive properties of adult human articular cartilage. Biochim Biophys Acta 1992; 1116: 147-54.

T, Kurosawa $\mathrm{H}$. The contact area and pressure distribution pattern of the knee. A study of normal and osteoarthrotic knee joints. Acta Orthop Scand 1980; 51: 871-9.

44 Vasan N. Effects of physical stress on the synthesis and degradation of cartilage matrix. Connect Tissue Res 1983; 12: 49-58.

45 Eyre D R, McDevitt C A, Billingham M E J, Muir $H$ Biosynthesis of collagen and other matrix proteins by articular cartilage in experimental osteoarthrosis. Biochem f 1980; 188: 823-37.

46 Brandt K D, Myers S L, Burr D, Albrecht M. Osteoarthritic changes in canine articular cartilage, subchondral bone, and synovium fifty-four months after transection of the anterior cruciate ligament. Arthritis Rheum 1991; 34: $1560-70$. 
47 Dedrick D K, Goldstein S A, Brandt K D, O'Connor B L, Goulet $R$ W, Albrecht $M$. A longitudinal study of subchondral plate and trabecular bone in cruciatedeficient dogs with osteoarthritis followed up for 54 months. Arthritis Rheum 1993; 36: 1460-7.

48 Flannery C R, Lark M W, Sandy J D. Identification of stromelysin cleavage site within the interglobular domain of human aggrecan-evidence for proteolysis at this site in vivo in human articular cartilage. $f$ Biol Chem 1992; 267: 1008-14.

49 Wu J-J, Lark M W, Chun L E, Eyre D R. Sites of stromelysin cleavage in collagen types II, IX, X, and XI of cartilage. f Biol Chem 1991; 266: 5625-8.

50 Dodge G R, Poole A R. Immunohistochemical detection and immunochemical analysis of type II collagen degra- dation in human normal, rheumatoid, and osteoarthritic articular cartilages and in explants of bovine articular cartilage cultured with interleukin-1. F Clin Invest 1989 83: $647-61$

51 Felson D T, Hannan M T, Naimark A, et al. Occupational physical demands, knee bending, and knee osteoarthritis: results from the Framingham study. $\mathcal{F}$ Rheumatol 1991 18: $1587-92$

52 Cooper C, McAlindon T, Coggon D, Egger P, Dieppe P. Occupational activity and osteoarthritis of the knee. Ann Rheum Dis 1994; 53: 90-3.

53 Kujala U M, Kaprio J, Sarna S. Osteoarthritis of weight bearing joints of lower limbs in former élite male athletes. BMF 1994; 308: 231-4. 